Rev. Int. Contam. Ambie. 37, 39-53, 2021

https://doi.org/10.20937/RICA.53660

\title{
CRITERIOS DE SELECCIÓN PARA UN SITIO DE DISPOSICIÓN FINAL DE RESIDUOS SÓLIDOS NO PELIGROSOS. REVISIÓN DE NORMAS AMBIENTALES LATINOAMERICANAS Y SU CONTRASTE CON LA NORMA ECUATORIANA
}

\author{
Selection's criteria for a non-hazardous solid waste disposal site. Review of latin american \\ environmental norms and their contrast with the ecuadorian regulation
}

\author{
Sandra Lucía COBOS MORA ${ }^{1,2 *}$, José Luis SOLANO PELÁEZ ${ }^{3,4}$ \\ y Paulo César GÁRATE RODRÍGUEZ ${ }^{5}$
}

${ }^{1}$ Carrera de Ingeniería Civil, Unidad Académica de Ingeniería Industria y Construcción, Universidad Católica de Cuenca, Ave. de las Américas y General Torrez (esq.) 010102, Cuenca, Ecuador.

${ }^{2}$ Departamento de Geografía Física y Análisis Geográfico Regional, Universidad de Sevilla, C/ San Fernando 4, 41004, Sevilla, España.

${ }^{3}$ Carrera de Ingeniería Ambiental, Unidad Académica de Ingeniería Industria y Construcción, Universidad Católica de Cuenca, Ave. de las Américas y General Torrez (esq.) 010102, Cuenca, Ecuador.

${ }^{4}$ Facultad de Filosofía y Letras, Universidad del Cuyo, Centro Universitario, 5500, Mendoza, Argentina.

${ }^{5}$ Carrera de Arquitectura, Unidad Académica de Ingeniería Industria y Construcción, Universidad Católica de Cuenca, Ave. de las Américas y General Torrez (Esq.) 010102, Cuenca, Ecuador.

*Autora para correspondencia: scobosm@ucacue.edu.ec/zhandry_cobos@yahoo.com

(Recibido: junio 2019; aceptado: marzo 2020)

Palabras clave: relleno sanitario, ubicación, aptitud del terreno, América Latina, Ecuador.

\section{RESUMEN}

En Latinoamérica, los sitios de emplazamiento de un relleno sanitario como tecnología de disposición final, se configuran como zonas altamente conflictivas desde una perspectiva socioambiental, lo que pudiera ser atribuible a los ineficientes procesos técnicos, administrativos y políticos que experimenta la región de forma generalizada. Además, al ser fuentes de contaminación en potencia generan una gran oposición ciudadana por las implicaciones en la salud pública y en los recursos naturales. Como consecuencia de las grandes cantidades de desechos que se generan por falta de empoderamiento en procesos de reutilización y reciclaje, para los países en vías de desarrollo aún es imperante contar con rellenos sanitarios en mayor número y superficie. En este contexto, cada país de la región ha desarrollado cuerpos legales anclados a sus respectivas políticas públicas, en donde establecen los criterios mínimos a cumplir para la implementación de un sitio de disposición final. El presente artículo realiza una revisión sistemática de 14 de estas normas latinoamericanas y su posterior comparación con las variables de la regulación ecuatoriana, con el fin de establecer oportunidades de mejora desde una perspectiva técnica y legal, que contribuyan a un desarrollo sustentable del Ecuador.

Key words: landfill, location, land suitability, Latin America, Ecuador. 


\begin{abstract}
In Latin America, landfill sites as a final disposal technology are configured as highly problematic areas from a socio-environmental perspective, attributable to inefficient technical, administrative and political processes that the region experiences in a generalized way. Furthermore, being a potential source of pollution, generate citizen opposition because of its implications for public health and natural resources. Due to the large amounts of waste generated by lack of empowerment in the reuse and recycling processes, it is imperative for developing countries to have sanitary landfills in greater numbers and areas. In this context, each country in the region has developed legal bodies anchored to their respective public policies, where they establish minimum criteria to be met for implementation of a final disposal site. Considering the former, this article carries out a systematic review of 14 Latin American standards and compares them with the Ecuadorian regulations, in order to establish opportunities for improvement, from a technical and legal perspective, which contributes to a sustainable development of Ecuador.
\end{abstract}

\section{INTRODUCCIÓN}

En pleno siglo XXI la gestión integral de residuos sólidos aún se presenta como un problema de trascendencia global, debido a sus implicaciones que repercuten sobre toda la humanidad. A nivel mundial se estima que de los años 2004 al 2050, la generación de residuos sólidos crecerá de 1.2 billones de t a 27 billones anuales (Majolagbe et al. 2017). Este hecho se atribuye principalmente a factores socio económicos, en donde se destaca: (i) mejoramiento en las condiciones de vida; (ii) una filosofía de consumo dependiente de factores culturales e históricos; (iii) procesos de urbanización con métricas como el número de habitantes, densidad poblacional, geografía del sector y normativa legal, entre otros (Lacoste y Chalmin 2006). Sólo en América Latina -región con el mayor crecimiento urbano del mundo (Terraza 2009)- se generan 160 millones de $t$ anuales de basura, con una proyección de crecimiento aproximada al año 2025 de 100 millones más al año (Hoornweg y Bhada-Tata 2012). De ello, sólo un 54 \% tendría una disposición final adecuada, a pesar de contar con casi el $93 \%$ de cobertura de recolección en las ciudades (Hernández-Berriel et al. 2016). Esto se atribuye a que en países con ingresos bajos se invierte más en sistemas de recolección que en procesos de disposición final, diferencia clave con países que presentan ingresos altos.

Acurio et al. (1997) visibilizaron una realidad latinoamericana poco afortunada en el ámbito de los residuos sólidos, fundamentada principalmente en una legislación simplista, con organismos de control inoperantes y una mala administración de los recursos económicos y técnicos, que originaron un servicio ineficiente. Esta realidad la evidencia Jiménez-Martínez (2015) al describir el escenario de la gestión integral de residuos sólidos (GIRS) en México. La situación anterior, entre otros factores, se debe a la subvención del gobierno, por la falta de responsabilidad y conciencia de la sociedad para pagar por el servicio público de la basura que desecha (Terraza 2009). Esto deriva en pasivos ambientales que desembocan en impactos negativos sobre la salud pública y sus consecuentes conflictos socio ambientales con las comunidades aledañas y los recicladores de base. El Banco Interamericano de Desarrollo (BID 2015) señala que este problema aún está lejos de resolverse, porque para el $45 \%$ de los residuos sólidos de la región aún no se tienen mecanismos adecuados de disposición final, menos aún una planificación adecuada, y sólo el $19.8 \%$ de los municipios presenta un plan de manejo.

En la actualidad, los países industrializados en Europa y Asia ya manejan modelos basados en la economía circular, lo que es ampliamente analizado por Korhonen et al. (2018) y Li et al. (2018). Esos modelos permiten alargar la vida útil de las materias primas y los objetos, mediante procesos de reutilización, remanufacturación y restauración, de forma que menos elementos se conviertan en basura y así se facilita su gestión. Para los países en vías de desarrollo, el manejo de una economía circular es factible (Ferronato et al. 2019), pero se enfrenta aún a fuertes problemas de sostenibilidad financiera, como son la inclusión de actores clave y la falta de regulaciones. Las razones antes expuestas llevan a continuar con un modelo económico lineal, por lo que la cantidad de residuos que llegan para una disposición final es cada vez mayor (Rúa-Restrepo et al. 2019). 
El mecanismo de disposición final depende principalmente del tipo de desecho que se genere. Sin embargo, la técnica del relleno sanitario (RS) es la más común en Latinoamérica, por ser económica y fácil de implementar. La Sociedad Americana de Ingenieros Civiles (ASCE, por sus siglas en inglés), la destaca como un mecanismo de protección al ambiente, a la salud y a la seguridad pública (Meléndez 2004). A pesar de estas consideraciones y como producto de un manejo inadecuado por la aplicación de prácticas desactualizadas, estos sitios se configuran como los principales generadores de impactos socioambientales negativos dentro de la GIRS (Sánchez-Arias et al. 2019). En un contexto global, estos espacios se han convertido en contaminantes a gran escala de fuentes hídricas, por la filtración del lixiviado (Majolagbe et al. 2017, Chopda y Malek 2018); del suelo, por la presencia de metales pesados (Ihedioha et al. 2017); del aire, por ser los causantes de al menos el $5 \%$ de las emisiones gaseosas y el $12 \%$ de la emisión de metano, segundo gas más común del efecto invernadero (Hoornweg y BhadaTata 2012). A lo anterior se suman, los malos olores, la alteración de la cubierta vegetal, la atracción de vectores y las afectaciones a la calidad de vida de las comunidades aledañas, entre otros. Para América Latina la realidad no difiere, tal como se muestra en estudios realizados en México y Colombia (Noguera y Olivero-Verbel 2010).

En Ecuador, la problemática es aún más crítica. Hasta la época de los años 90, se disponía sólo de botaderos a cielo abierto con escasos o nulos controles. Estos sitios empezaron a colapsar de acuerdo con las condiciones demográficas y actividades productivas de la zona a la que servían (Solíz-Torre 2015), dando origen a una fuerte crisis sanitaria. Hasta finales del siglo XX se da paso a la construcción de los primeros RS, de modo que para el año 2013, el $17 \%$ de los cantones contaban con infraestructura de este tipo, cifra que aumentó al $45 \%$ para el año 2017. A pesar del crecimiento en la construcción de sitios de disposición final, se recibe únicamente el $87 \%$ de los residuos sólidos, lo que corresponde a $12000 \mathrm{t} / \mathrm{d}$ aproximadamente, por lo que alrededor de $1000 \mathrm{t} / \mathrm{d}$ tienen aún una disposición final inadecuada (INEC 2018). Esta realidad parte de una producción per cápita en la zona urbana de $0.86 \mathrm{~kg} / \mathrm{hab} / \mathrm{d}$, valor inferior al $1.09 \mathrm{~kg}$ de la media latinoamericana y aún menor a la media a nivel mundial de $1.19 \mathrm{~kg}$ (Hettiarachchi et al. 2018), pero superior a lo registrado por países como Venezuela, Colombia y Bolivia.

En la actualidad, son más limitados los espacios sobre los cuales construir un RS porque deben cumplir regulaciones y a su vez minimizar los costos ambientales, económicos y sociales. Además, existe una desacertada planificación territorial con dinámicas poblacionales que disminuyen las opciones, como lo son la expansión de las zonas urbanas, el crecimiento económico de los pueblos, las afectaciones en propiedades aledañas, la competencia por el espacio físico, y los usos de suelo incompatible. QuinteroTorres (2017) ratifica lo anterior cuando afirma que los países latinoamericanos todavía presentan una débil gestión territorial para ubicar infraestructura de esta índole, debido a una falta de visión integral del territorio.

La correcta delimitación de un sitio para emplazar un RS repercutirá finalmente en la optimización de recursos reflejado en: (i) optimización en la fase de transporte de los residuos sólidos (ruta desde los nodos generadores hasta el RS); (ii) mejor control de los impactos ambientales, mismos que se pueden expandir hasta $7 \mathrm{~km}$ a la redonda (González-Díaz 2016); y (iii) mayor cantidad de residuos sólidos dispuestos en el RS. Este último aspecto estará ligado al crecimiento poblacional, nivel de consumo de la zona servida, entre otros factores. La Corte Europea de Derechos Humanos en el año 1999 establece una relación entre el derecho a la vida y la correcta operación de sitios de disposición final (Gran-Castro y Bernache-Pérez 2015), lo que lo convierte en un problema social y no sólo en uno ambiental.

Para 1999, Latinoamérica contaba con la cartera más activa de proyectos en el ámbito de la gestión de residuos sólidos del Banco Mundial, destacándose países como Brasil, Colombia, Argentina y Paraguay (Johannessen y Bayer 1999). En la actualidad, este hecho difiere, tal es el caso que Abujayyab et al. (2016) en un revisión literaria sobre criterios y métodos para la selección de un sitio de disposición final, evidencia dos aspectos importantes: (i) que el continente americano posee la menor cantidad de estudios científicos en esta área; y (ii) el $60 \%$ de los criterios utilizados en la toma de decisión, se acogen a las normativas vigentes en cada país.

Frente a todo lo expuesto, el objetivo de este estudio es realizar una revisión sistemática de los criterios mínimos normados en Latinoamérica para ubicar sitios de disposición final de residuos sólidos no peligrosos. Para ello, se revisarán las normativas de países de la región y se compararán con las variables de la regulación ecuatoriana, con el fin de establecer oportunidades de mejora desde un aspecto técnico y legal que contribuyan a un desarrollo sustentable del Ecuador. 


\section{MÉTODOS}

Este estudio comprendió un análisis comparativo y de frecuencia de 14 normas latinoamericanas de regulación ambiental orientadas al modelo de gestión para el manejo de residuos sólidos. En específico en el ámbito de la delimitación de un sitio para la disposición final en los países de Bolivia, Chile, Colombia, Costa Rica, Honduras, México, Nicaragua, Panamá, Paraguay, Perú, El Salvador, Venezuela, Argentina y República Dominicana, detalladas en el cuadro I. Estos cuerpos legales están vigentes hasta la fecha de ejecución de la investigación. Posteriormente, se contrastó con los criterios dispuestos en el Reglamento al Código Orgánico del Ambiente (COA) para el manejo y disposición final de desechos sólidos no peligrosos en el Ecuador, vigente desde el 12 de junio de 2019. El mencionado cuerpo legal se complementa a través del artículo 596 y sus disposiciones transitorias con el Texto Unificado de Legislación Segundaria de Medio Ambiente (TULSMA) (MAE 2015), que corresponde a una actualización del Registro Oficial Suplemento 2 de 31 de marzo de 2003, que contempla la Norma de calidad ambiental (NCA) para el manejo y disposición final de desechos sólidos no peligrosos (MAE 2003). Este último especifica los criterios mínimos a cumplir para la ubicación de un RS.

\section{RESULTADOS Y DISCUSIÓN}

En el contexto latinoamericano y luego del análisis de los cuerpos legales referidos, se obtuvieron 36 criterios mínimos a cumplir para la ubicación óptima de un sitio de disposición final, detallados en el cuadro II. Los criterios han sido clasificados en cuatro categorías que son: social, técnica, económica y ambiental. E1 $36 \%$ corresponde a la categoría social, el $28 \%$ a la técnica, el $25 \%$ a la económica y el $11 \%$ a la ambiental. A simple vista, el componente social lideraría la selección de un sitio para un RS. Sin embargo, de acuerdo con el análisis de frecuencias (Fig. 1), se observa que de los criterios dentro de esta categoría, el $69 \%$ se contemplan en máximo dos países, y tan sólo el $31 \%$ restante, constituido por cuatro criterios básicos, son contemplados en más países. De estos cuatro criterios, el primero, referenciado en el $86 \%$ de las normas, corresponde a la evaluación de las distancias a zonas urbanas y de expansión, por los riesgos que implica en la salud pública (Ogunrinola y Adepegba 2012, Palmeira-Wanderley et al. 2017). El segundo, considerado en el $64 \%$ de las normas corresponde a la distancia a aeropuertos por el peligro que puede representar para un avión, ya sea por una explosión (Abd-El Monsef y Smith 2019) u obstáculos aéreos que pongan en riesgo los procesos de vuelo (Dar et al. 2019). El tercero, se refiere a la conservación de zonas de patrimonio cultural, que se encuentra en el $43 \%$ de las normas. Finalmente, el cuarto criterio, de uso y ocupación del suelo, se presenta en el $29 \%$ de las normas. Este tiene como objetivo proteger a los ecosistemas altamente amenazados por la contaminación que generan los residuos sólidos y la incorrecta ubicación de un RS, criterio que se encuentra supeditado a la estructura de conservación propia de cada país.

Como una marcada tendencia en la región, el componente social no goza de la importancia que amerita. Esto evidencia una inobservancia por parte de las autoridades por los derechos ambientales, al no ejercer un control oportuno sobre la contaminación, presente aún más a nivel de implementación y operación de un RS. El derecho ambiental se entiende como un subsistema normativo que regula y pone límites a las actividades administrativas, políticas y humanas para proteger la naturaleza y no sólo como una lista de criterios que se cumplen a discreción. Este derecho es una rama particular muy cambiante por su constante evolución, que supera los esquemas del derecho común, en especial por el flujo de su transformación (Sanfelice et al. 2016). Como consecuencia, los RS se consolidan como infraestructura no deseada y generan una fuerte oposición ciudadana (Colebrook y Sicilia 2007), que fortalece el axioma social "no en mi patio" (NIMBY, por sus siglas en inglés) (Sun et al. 2016). Este axioma también se ha utilizado en países en vías de desarrollo como se ha podido apreciar en Argentina (Walsh 2007) y Chile (Carrasco y Milic 2017). Según Gran-Castro y Bernache-Pérez (2015), las barreras sociales se producen por la insuficiente capacidad de las autoridades locales para cumplir con la responsabilidad de gestión en el ámbito de los residuos sólidos.

Por lo tanto, es necesario implementar procesos metodológicos participativos con la ciudadanía y no meramente informativos, que vinculen individuos de diferentes áreas, competencias, valores sociales y agendas políticas, para mejorar la comprensión de la idoneidad de un sitio para la disposición final, a través de sus situaciones, necesidades, y objetivos. Finalmente, se pretende acentuar en una decisión reflexiva que minimice al máximo la oposición pública y transforme a la GIRS en un sistema legítimo y sustentable (Latargère 2019). Estos espacios de díalogo permiten abordar la importancia de conflictos socio-ambientales como: prácticas de gestión de las autoridades, sobretensión de la capacidad de 
CUADRO I. NORMATIVAS AMBIENTALES LATINOAMERICANAS ANALIZADAS EN ESTE ESTUDIO.

\begin{tabular}{|c|c|c|}
\hline País & Cuerpo legal & Fuente \\
\hline Bolivia & Norma Boliviana NB 742-760: Norma de residuos sólidos. & (Ministerio de Desarrollo Humano 1996) \\
\hline Chile & $\begin{array}{l}\text { Decreto 189: Reglamento sobre condiciones sanitarias y de } \\
\text { seguridad básica en los rellenos sanitarios }\end{array}$ & (Presidencia de la República de Chile 2008) \\
\hline Colombia & $\begin{array}{l}\text { Decreto 838. Modificación del Decreto } 1713 \text { de } 2002 \text { sobre } \\
\text { disposición final de residuos sólidos. }\end{array}$ & (Presidencia de la Republica de Colombia 2005) \\
\hline Costa Rica & $\begin{array}{l}\text { Decreto Ejecutivo No } 38928-\mathrm{S} \text { : Reglamento sobre rellenos } \\
\text { sanitarios }\end{array}$ & (Presidencia de la República de Costa Rica 2014) \\
\hline Honduras & $\begin{array}{l}\text { Acuerdo No. 378-2001: Reglamento para el manejo de } \\
\text { residuos sólidos }\end{array}$ & $\begin{array}{l}\text { (Presidencia Constitucional de la República de } \\
\text { Honduras 2001) }\end{array}$ \\
\hline México & Norma Oficial Mexicana NOM-083 & (SEMARNAT 2004) \\
\hline Nicaragua & $\begin{array}{l}\text { NTON } 05 \text { 013-01: Norma Técnica para el control ambiental } \\
\text { de los rellenos sanitarios para desechos sólidos no peligrosos }\end{array}$ & (MARENA 2002) \\
\hline Panamá & $\begin{array}{l}\text { Decreto Ejecutivo No } 275 \text { : Normas de los rellenos sanitarios, } \\
\text { con capacidad mayor o igual a trescientas toneladas métricas } \\
\text { por día, de residuos sólidos no peligrosos. }\end{array}$ & (Presidencia de la República de Panamá 2004) \\
\hline Paraguay & $\begin{array}{l}\text { Resolución } \mathrm{N}^{\circ} \text { 282: Criterios para la selección de áreas para } \\
\text { la disposición final de residuos sólidos en rellenos sanitarios }\end{array}$ & (SEAM 2004) \\
\hline Perú & $\begin{array}{l}\text { Reglamento del Decreto Legislativo N N 1278: Ley de Gestión } \\
\text { Integral de Residuos Sólidos }\end{array}$ & (Presidencia de la República del Perú 2017) \\
\hline El Salvador & $\begin{array}{l}\text { Decreto Ejecutivo } N^{\circ} 42 \text { : Reglamento Especial sobre el } \\
\text { manejo integral de los desechos sólidos y sus anexos }\end{array}$ & $\begin{array}{l}\text { (Presidencia de la República de El Salvador } \\
\text { 2002) }\end{array}$ \\
\hline Venezuela & $\begin{array}{l}\text { Decreto 2216: Normas para el manejo de los desechos sólidos } \\
\text { de origen doméstico, comercial, industrial, de cualquier otra } \\
\text { naturaleza que sean peligrosos }\end{array}$ & $\begin{array}{l}\text { (Presidencia de la República Bolivariana de } \\
\text { Venezuela 1992) }\end{array}$ \\
\hline Argentina & Ley 25.916. Gestión de residuos domiciliarios & (Congreso Argentino 2004) \\
\hline $\begin{array}{l}\text { República } \\
\text { Dominicana }\end{array}$ & $\begin{array}{l}\text { Norma para la gestión ambiental de residuos sólidos no } \\
\text { peligrosos }\end{array}$ & $\begin{array}{l}\text { (Secretaría de Estados de Medio Ambiente y } \\
\text { Recursos Naturales de República Dominicana } \\
\text { 2003) }\end{array}$ \\
\hline Ecuador & $\begin{array}{l}\text { Anexo 6: Norma de calidad ambiental para el manejo y } \\
\text { disposición final de desechos sólidos no peligrosos. }\end{array}$ & (MAE 2003) \\
\hline
\end{tabular}

resiliencia del medio ambiente, empobrecimiento del espacio de vida, el despojo del territorio, entre otros (Venegas-Sahagún 2018).

La segunda categoría corresponde al grupo de las variables técnicas, consideradas todas aquellas que representan o involucran un trabajo de tecnología o ingeniería. De este grupo, las más frecuentes de acuerdo con la figura 2 son cinco. La primera, contemplada en el $93 \%$ de las normas, hace referencia a la restricción de las zonas de inundación. La segunda, en un $86 \%$ de las normas, considera a la estabilidad geológica para evitar daños en la infraestructura civil, contaminación del suelo y de fuentes de agua.
Por ello, se debe guardar distancia de factores como fallas geológicas, deslizamientos, asentamientos, entre otros. La tercera, contemplada en el $50 \%$ de las normas, hace referencia a las características mecánicas del suelo, como la permeabilidad, para evitar la filtración de lixiviados. Musso et al. (2017) recomiendan a las arcillas como barreras hidráulicas para impedir el flujo de lixiviados. La cuarta variable es la disponibilidad del material de cobertura; que al igual que la anterior es aplicada en el $50 \%$ de las normas. La quinta variable, estipulada en el $43 \%$ de las normas, hace referencia a no afectar obras civiles de conducción y comunicación como 
CUADRO II. CRITERIOS APLICADOS EN NORMATIVAS LATINOAMERICANAS

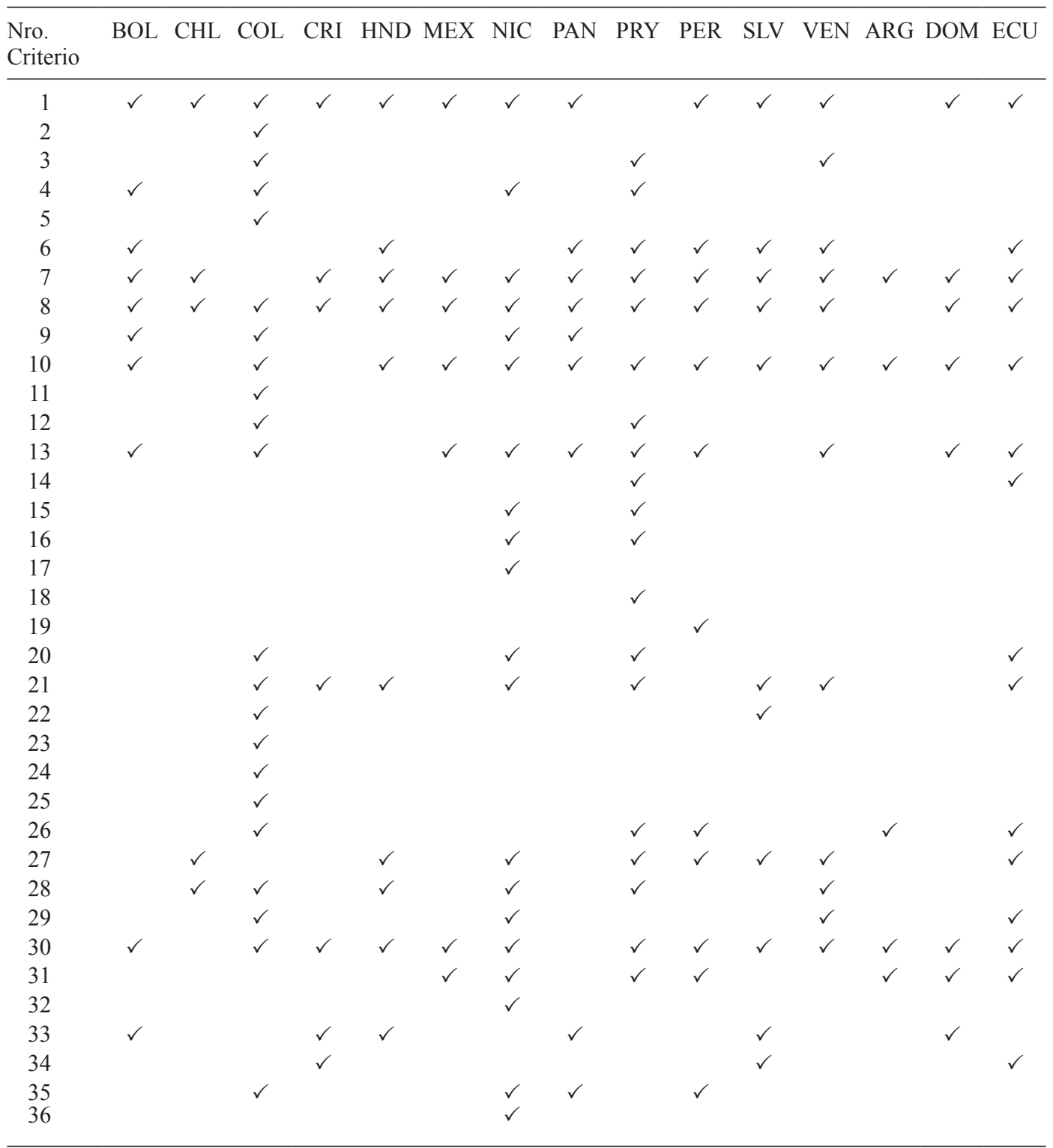

Nota 1. Las siglas de los países corresponde a la norma ISO 3166-1 alfa-3.

Nota 2. 1 = Inestabilidad geológica, $2=$ Geoformas del área, $3=$ Pendiente, $4=$ Tipo de suelo, $5=$ Vulnerabilidad sísmica, 6 = Características mecánicas del suelo, $7=$ Zona de Inundación, $8=$ Cuerpos de agua superficiales o subterráneos, $9=$ Cuenca hidrográfica, $10=$ Afectación a zonas urbanas y expansión, $11=$ Costo de transporte desde la zona urbana, $12=$ Densidad poblacional, $13=$ Aeropuertos, $14=$ Distancia a viviendas, $15=$ Distancia a centros educativos, $16=$ Distancia a centros de salud, $17=$ Distancia a zonas industriales de alimentos, 18 $=$ Distancia al centro de recolección, $19=$ Distancia a granjas, $20=$ Distancia a vías, $21=$ Accesibilidad de vías, 22 = Condiciones de la vía de acceso, 23 = Pendiente de la vía, $24=$ Número de vías de acceso, $25=$ Tráfico, 26 = Uso y ocupación del suelo, $27=$ Disponibilidad de material de cobertura, $28=$ Distancia al material de cobertura, $29=$ Calidad del material de cobertura, $30=$ Áreas naturales protegidas, $31=$ Zonas de patrimonio cultural, 32 = Sitios turísticos, 33 = Infraestructura civil de conducción, $34=$ Servicios básicos, $35=$ Clima, 36 = Límites municipales.

oleoductos, gaseoductos, poliductos, acueductos, canales, alcantarillado, tendido eléctrico y más de esta misma índole.
De acuerdo a la literatura, componentes de la categoría técnica, pueden también ser valorados como ambientales o económicos. Es así que, Şener et al. 


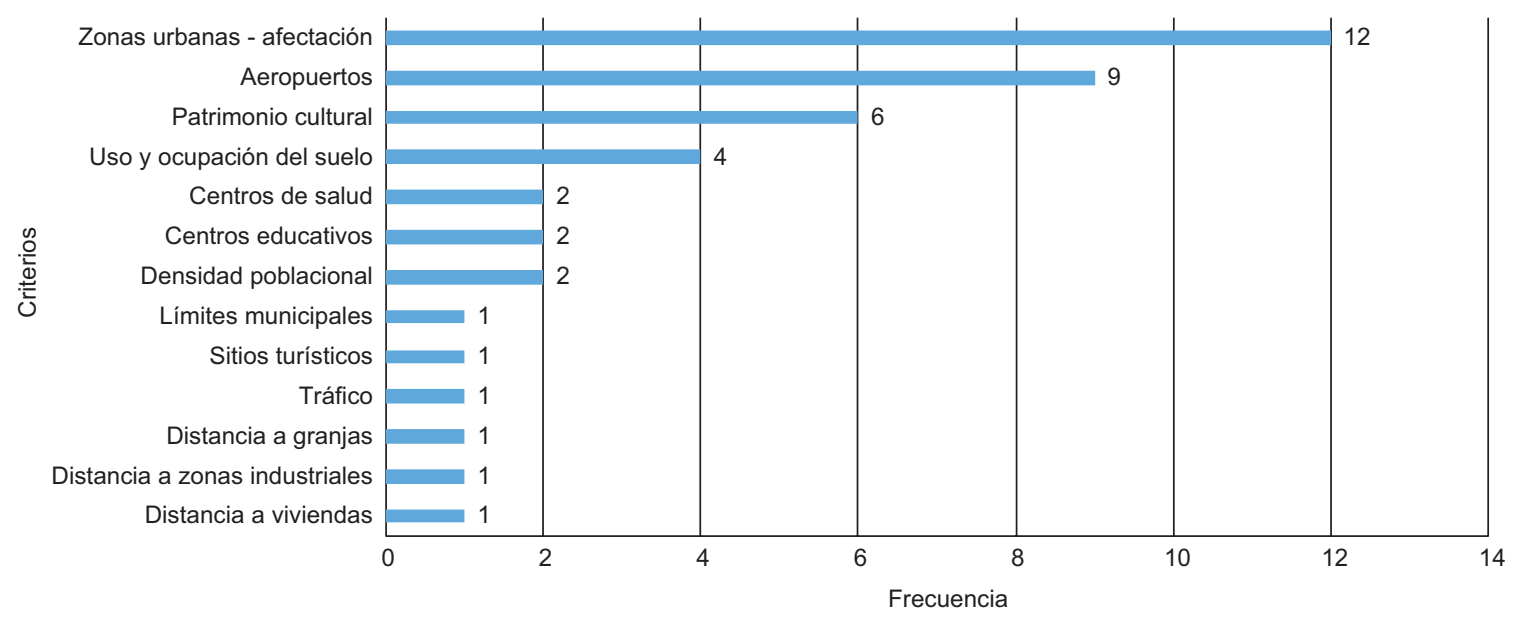

Fig. 1. Análisis de frecuencia de variables sociales.

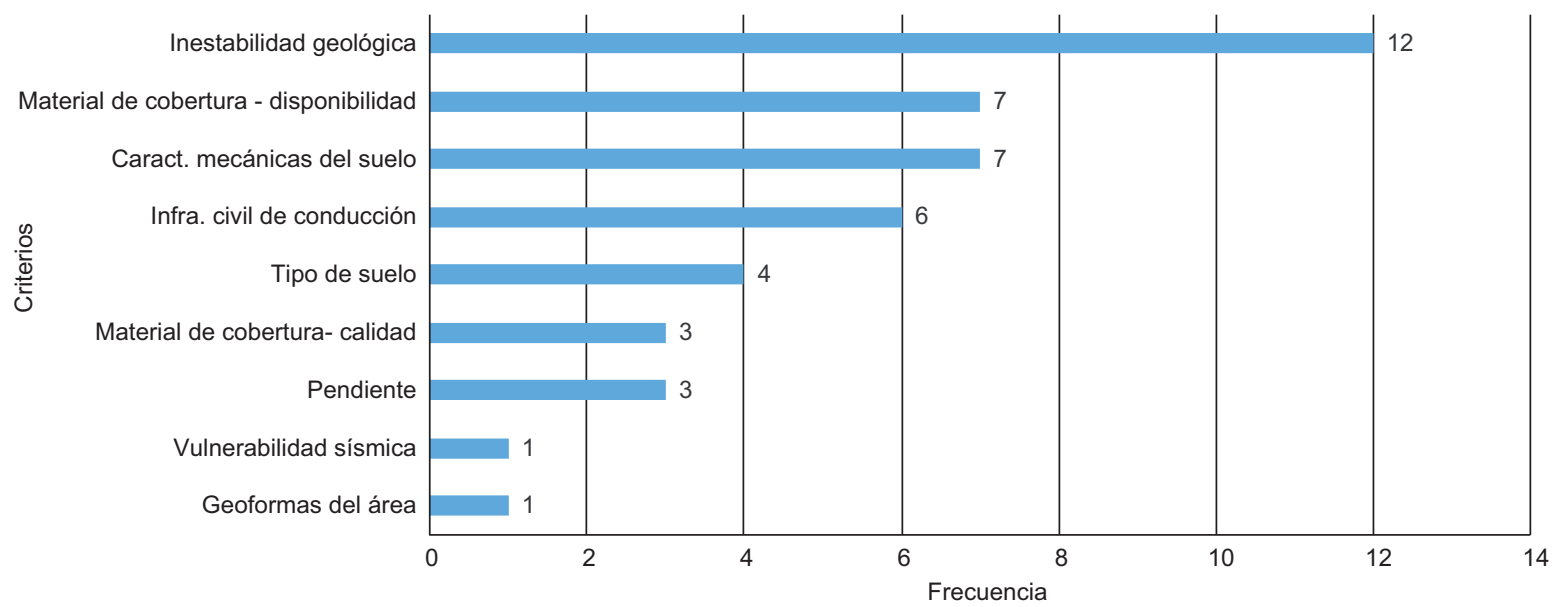

Fig. 2. Análisis de frecuencia de variables técnicas.

(2010), Alavi et al. (2013), Barakat et al. (2017) y Rahmat et al. (2017) los analizan desde su rol de protección al suelo y a las fuentes hídricas. Por otro lado, las pendientes son evaluadas en términos económicos por los costos de excavación que implican; excepto en Wang et al. (2009), Gorsevski et al. (2012), Uyan (2014), Elahi y Samadyar (2015) entre otros, donde también la consideran como un factor ambiental, porque a pesar de recalcar su costo, priorizan la afectación a procesos paisajísticos por favorecer el drenaje de lixiviado. En contraste con estos autores, Şener et al. (2011) y Demesouka et al. (2013) agrupan estos criterios en morfológicos y geológicos, y es consideración que comparten los cuerpos legales de Bolivia y República Dominicana. En Paraguay, se comparte el criterio de esta investigación y denota la existencia de componentes técnicos
En lo que respecta a las variables ambientales y de acuerdo con la figura 3 , el criterio más importante recae en la distancia a cuerpos de agua para evitar la contaminación de las fuentes superficiales y subterráneas. Este criterio está presente en un $93 \%$ de las normas. Luego, en un $86 \%$ de las normas se contemplan áreas protegidas para conservar zonas ecológicamente sensibles. Las menos recurrentes por estar en el $29 \%$ de las normas son el clima y las cuencas hidrográficas. La primera, con mayor énfasis en la velocidad y dirección del viento para evitar la dispersión de malos olores propios de infraestructuras de esta índole, que, entre otros factores, tiene fuertes implicaciones en la salud pública de comunidades cercanas (Ogunrinola y Adepegba 2012), por lo que favorece al axioma social NIMBY (Salleh et al. 2017). La segunda, pretende evitar contaminación en 


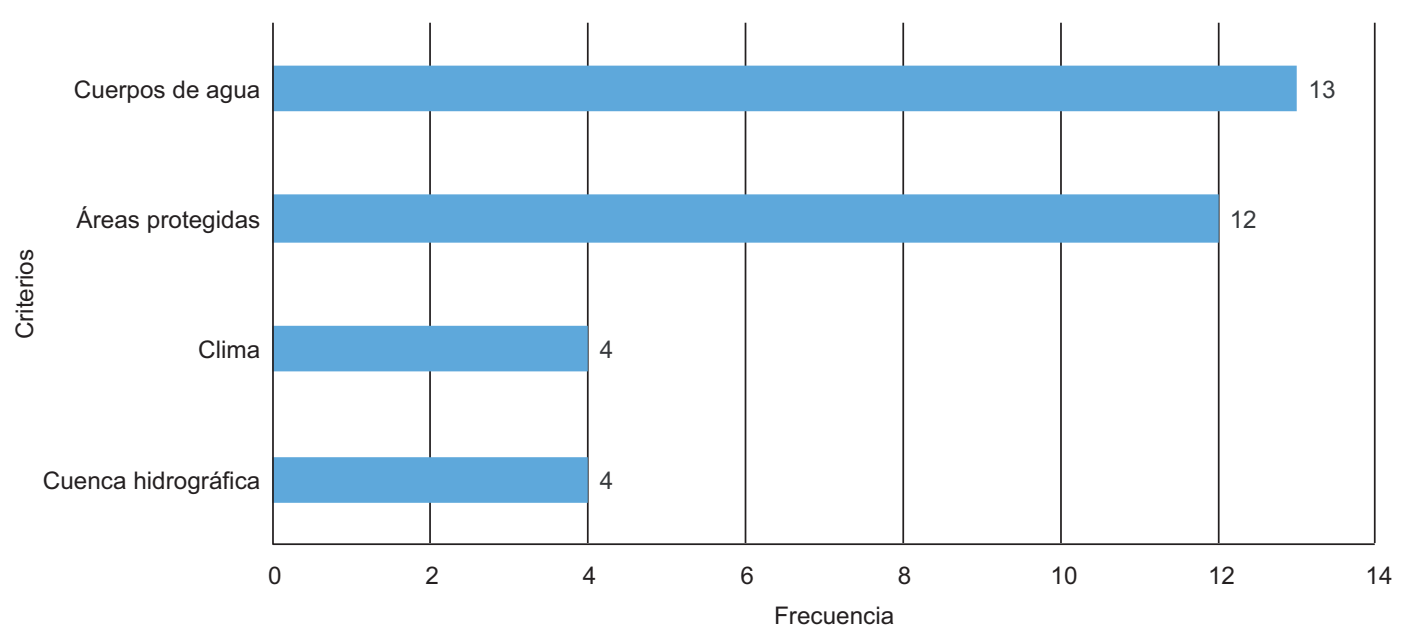

Fig. 3. Análisis de frecuencia de variables ambientales

las partes altas de las cuencas para impedir complicaciones ambientales con las poblaciones asentadas en la parte baja.

El componente ambiental se fundamenta en un desarrollo sustentable y planificación sostenible, a través de la protección de los ecosistemas ante posibles factores contaminantes, que debe orientar los esfuerzos de las autoridades en implementar de formar legítima y legal, áreas de protección para la conservación y la producción. Más aún cuando la naturaleza no cuenta con la suficiente capacidad receptora para la excesiva cantidad de residuos sólidos que se generan diariamente (Solíz-Torre 2015). A lo anterior se añade el impacto ambiental negativo por los hábitos de consumo, el abandono de las zonas rurales y el incremento del porcentaje de materia inorgánica, que a diferencia de la materia orgánica, es difícil de reinsertar en los sistemas ecológicos (Vera-Toledo y González-Herrera 2010). Los criterios técnicos y ambientales que tienen como finalidad evitar la contaminación en el aire, suelo y agua, suman el $39 \%$ de todos los criterios, por lo que se constituyen en la mayor fuerza en la definición de un sitio para emplazar un RS en Latinoamérica. Se puede evidenciar que de los nueve criterios más comunes, por contemplarse en el $50 \%$ o más de las normas, el $67 \%$ pertenece a estas categorías.

Por último, el aspecto económico apunta a la sostenibilidad del sistema, en donde se resalta el alto costo que significa el traslado de los residuos sólidos desde las urbes hasta el sitio de disposición final (Gascón et al. 2015), y su posterior cobertura con material idóneo. Según el análisis de frecuencia (Fig. 4), la importancia recae sobre dos criterios: el primero, abordado en el $50 \%$ de las normas, co- rresponde a la disponibilidad y accesibilidad de vías indistintamente de la época del año; y el segundo, a la distancia al material de cobertura, como la base de la operación de un RS y se encuentra en el $43 \%$ de las normas.

Desde otra perspectiva, las normas de Colombia, Nicaragua y Paraguay incluyen más del $50 \%$ de los criterios analizados en el presente estudio, con 22, 20 y 19 respectivamente. Estos países incluyen variables específicas, de aplicación exclusiva en su país y representan el $33 \%$ del total de variables analizadas. En este grupo se encuentran el $46 \%$ de las variables sociales (6 de 13), el $44 \%$ de las económicas (4 de $9)$, un $20 \%$ de las técnicas y ninguna ambiental.

Colombia es el único país que contempla el costo del transporte desde la zona urbana, pendiente de la vía, número de vías, tráfico, geoformas del área y vulnerabilidad sísmica. A pesar de ello, tiene una deficiencia al no contemplar zonas inundables que preservan el flujo de agua, lo que repercutiría sobre la estabilidad de la infraestructura. Otra característica de esta norma es la dicotomía en el abordaje de los centros urbanos. Por un lado promueve la conservación de una distancia prudencial para disminuir conflictos sociales, y por otro, motiva su proximidad con el fin de no incurrir en costos elevados por los procesos de transporte de residuos sólidos. Esta normativa, más que un cuerpo legal, se configura como una guía técnica ambiental, que a más de las regulaciones mínimas, proporciona una metodología de valoración y puntuación para un análisis multicriterio.

Nicaragua es el único país en incluir distancia a zonas industriales, sitios turísticos y a los límites municipales. Por último, sólo Paraguay contempla distancias a centros de recolección y a las viviendas 


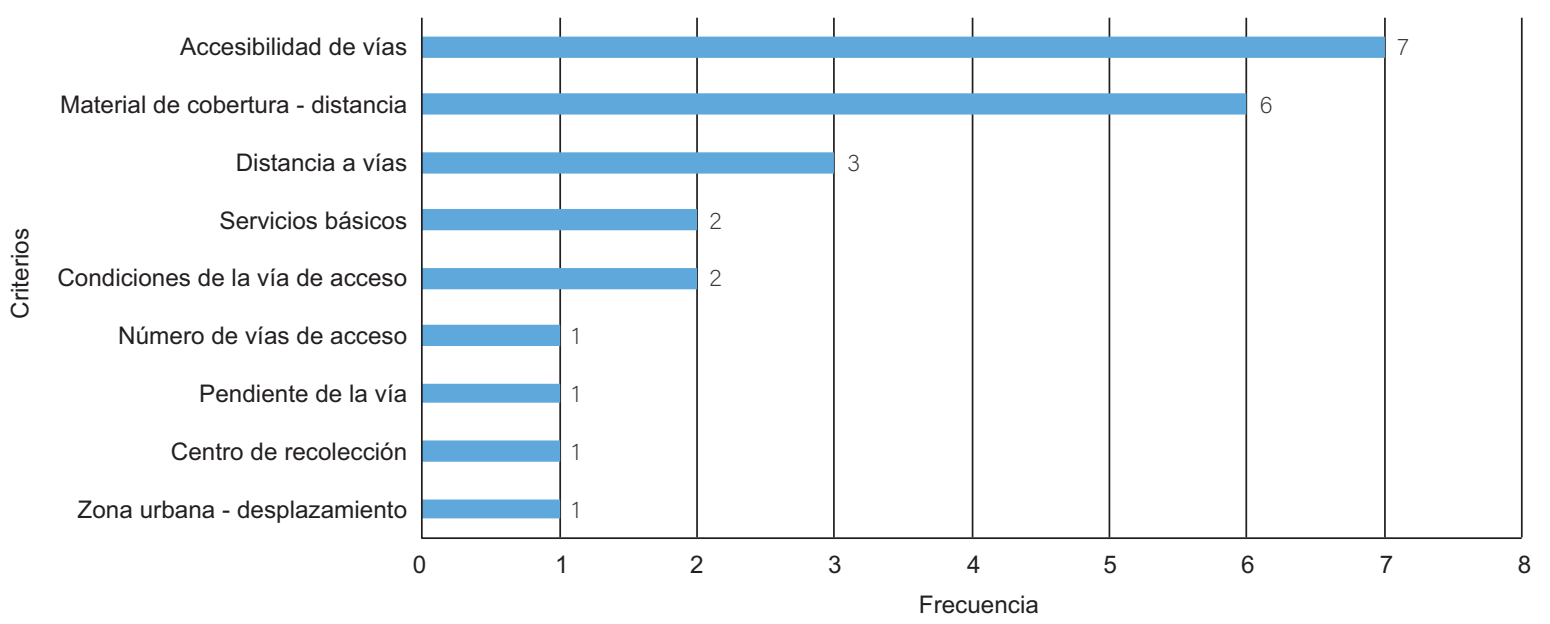

Fig. 4. Análisis de frecuencia de variables económicas

más próximas. A estos criterios se suman distancias a granjas, que se contempla sólo en Perú.

El 79\% de los países, conformados por los once restantes, excluyendo Colombia, Nicaragua y Paraguay analizados anteriormente, abordan menos de $32 \%$ del total de criterios analizados. Las legislaciones promulgadas en Chile y Argentina en el ámbito de la GIRS, presentan una estructura simple y detalles básicos, ya que abordan sólo cinco criterios. Sin embargo, Chile en su acápite de diseño y operación de un sitio de disposición final, contempla aquellas variables técnicas que finalmente se orientan a garantizar que con la aplicación de tecnologías y diseños adecuados, se puede precautelar el ambiente y a las poblaciones aledañas. Esto repercutirá en un aumento considerable de costos en la fase de operación y mantenimiento del RS.

En el Ecuador, la aún vigente NCA coincide con el $42 \%$ de los criterios ( 15 de 36 ) que son: zonas de inundación, cuerpos de agua superficiales o subterráneos, inestabilidad geológica, afectación a zonas urbanas y de expansión, áreas naturales protegidas, aeropuertos, características mecánicas del suelo, accesibilidad de vías, disponibilidad de material de cobertura, zonas de patrimonio cultural, uso y ocupación del suelo, distancia a vías, calidad del material de cobertura, servicios básicos y distancia a viviendas. Entre ellos, contiene a los nueve más recurrentes, e incluye un nuevo criterio que contempla áreas previstas para proyectos de desarrollo regional o interés nacional, como es el caso de las hidroeléctricas, los embalses multipropósito y la minería a gran escala, entre otros.

Cabe destacar que el más alto deber del Estado, previo a la implantación de un proyecto de esta índole, es garantizar la protección del patrimonio natural y cultural del país. Los artículos 3 y 14 de la Constitución de la República del Ecuador, regulan este hecho al estipular el cuidado de las áreas nacionales protegidas y de recreación, en pro de la preservación, la conservación, la biodiversidad y la integridad del patrimonio genético, la prevención del daño ambiental y la recuperación de los espacios naturales degradados. Para hacer efectiva esta garantía, es necesario evocar en el contenido de la Constitución a los artículos 261, numeral 7; 276, numeral 4; 395, numeral 1; 400, 401, 402, 403, 404 y 406 que atribuyen competencias centrales y exclusivas sobre las áreas naturales protegidas y los recursos naturales. El objetivo fundamental es garantizar a las personas y colectividades el acceso equitativo y permanente al agua, aire y suelo, y a los beneficios de los recursos del subsuelo y del patrimonio. Para ello, el Estado garantizará un modelo sustentable de desarrollo, equilibrado desde el punto de vista ambiental y respetuoso de la diversidad cultural, donde conserve la biodiversidad y la capacidad de regeneración natural de los ecosistemas. De esta manera, asegura la satisfacción de las necesidades de las nuevas generaciones y ejerce soberanía sobre la biodiversidad a través de la declaración de las áreas protegidas como interés público, incluidas las formaciones físicas, biológicas y geológicas, cuyo valor desde el punto de vista ambiental, científico, cultural o paisajístico, exige su protección, conservación, recuperación y promoción (Asamblea Nacional Constituyente 2008).

Desde la Constitución y con base en lo expuesto, el estado central, y los gobiernos autónomos descentralizados (GAD), en cualquier jurisdicción del país, deben partir de manera obligatoria de una adecuada identificación de las áreas de conservación natural 
y cultural en los procesos de planificación e implementación de un RS. Ello implica que en ejercicio de las competencias para la regulación del uso del suelo, los GAD, con base en el artículo 54 del Código Orgánico de Organización Territorial, Autonomía y Descentralización (COOTAD) (Asamblea Nacional de la República del Ecuador 2010) deben promover la creación de ordenanzas con un inventario de estas áreas en cada jurisdicción, incluidas las que corresponden a la protección del estado central, para fines de coordinación. Para lo anterior, se considerarán también los criterios y lineamientos que otorga la Ley Orgánica de Ordenamiento Territorial, Uso y Gestión del Suelo (LOOTUGS) (Asamblea Nacional de la República del Ecuador 2016). Identificadas las zonas, es indispensable que se fijen las políticas públicas de protección y sustentabilidad de las áreas referidas. Si para su ejecución es necesaria la declaración de utilidad pública, las autoridades centrales y seccionales en el ámbito de sus competencias deben consolidar un plan de gestión con medidas cautelares y previas, a fin de evitar intervenciones anticipadas que afecten estos territorios.

En este marco, y anclado a la LOOTUGS, es importante reestructurar los planes de ordenamiento territorial, los planes de uso y gestión del suelo y zonificación ecológica puesto que por la reciente expedición de este cuerpo legal no se ha tenido una acertada articulación con la NCA. Las autoridades deberían inventariar con claridad las zonas urbanas, de expansión urbana y rurales pobladas, con sus zonas de producción agrícola, en consideración con un plan de desarrollo integral a largo plazo. Sólo una vez cumplido con este mapeo, la acción siguiente es demarcar las áreas libres, y sobre ellas, las áreas posibles de implantación de un RS, con base en los criterios analizados en este estudio.

Con la identificación de las áreas probables de emplazamiento de un RS, con fines de planificación integral, es necesario generar espacios que propicien conciencia colectiva sobre la protección del ambiente. No se trata sólo de reconocer que en el siglo XXI la naturaleza tiene derechos. Es necesario trascender el pensamiento tradicional de considerar a la naturaleza como un mero objeto que sirve para enterrar los desechos o para la explotación de recursos, a contextualizarla como sujeto de derecho y parte sustancial de la supervivencia humana. Se entiende que al igual que el ser humano, la naturaleza es un ser vivo y que la concepción antropocéntrica de mirar al ser humano como el centro de todo, ya no tiene tanta relevancia en la actualidad. Hoy se depende más de la naturaleza y sus cambios, que del hombre para su sustentabilidad en el futuro. Ello implica el análisis de su intervención como afección al derecho del buen vivir y la aplicación de medidas compensatorias. Esto ratifica la necesidad de un proceso de participación ciudadana efectivo, pilar fundamental del componente social.

Sobre la base de lo antes expuesto, es claro que abordar la temática de la identificación de un sitio para la construcción de un RS representa, en el ámbito jurídico, el conocimiento de las garantías constitucionales de vivir en un ambiente libre de contaminación. Esta concepción, en ciertos municipios, se limita a considerar que basta con encontrar un terreno amplio y alejado de la población para convertirlo en un botadero de basura, sin medir las consecuencias del daño que ello produce al ecosistema por la generación de pasivos ambientales. Esta práctica en el Ecuador, con la expedición del COA y su Reglamento en el artículo 596 (Presidencia de la República del Ecuador 2019), debe concluir. Para ello se ha dispuesto, en norma expresa, sellar los botaderos existentes mediante proyectos de cierre técnico autorizados por la Autoridad Ambiental Nacional y emprender la búsqueda de espacios adecuados que cumplan con los criterios mínimos para garantizar que la última fase de la GIRS se realice de forma sanitaria, a través de procesos de aislamiento y confinación.

Se considera que se debe requerir a los GAD asumir la competencia establecida en el artículo 55 literal d) del COOTAD (Asamblea Nacional de la República del Ecuador 2010), en donde llama a los municipios a buscar soluciones integrales para la disposición final de residuos. Esto es importante porque al tratar de solucionar el problema de la ubicación de un RS, no se puede pensar en forma aislada de los procesos de recolección, transporte y tratamiento (estas tres últimas fases no han sido objeto de estudio en la presente investigación). El mencionado servicio público está anclado a una política pública nacional supeditada a las disposiciones de normativas de bioseguridad y control determinadas por la autoridad sanitaria nacional, reguladas en los artículos 99, 100 y 103 de la Ley Orgánica de Salud (Congreso Nacional del Ecuador 2006), en concordancia con los artículos 228, 229, 230, 231, 232, 233 y 234 del COA (Asamblea Nacional de la República del Ecuador 2017). En consecuencia, las normas a través de las cuales se establecen los procedimientos técnicos de la GIRS, que a su vez provienen de una disposición legal con carácter constitucional y orgánica, deben observar que como mínimo en el proyecto de selección de un 
territorio para un RS, se prevea la posibilidad de que en él se puedan aplicar proyectos de investigación y desarrollo de tecnologías para los procesos clave que componen el modelo de gestión a nivel nacional: acceso de vehículos, recolección, transporte, tratamiento, almacenamiento temporal y definitivo, clasificación, entre otros.

\section{CONCLUSIONES}

Luego de la revisión de los cuerpos legales latinoamericanos en materia de la gestión de residuos sólidos no peligrosos, se establecen estrategias en beneficio de la población servida y factibles a un mejoramiento continuo. A su vez, este estudio invita a la colectividad a repensar su concepto de desarrollo en función de la protección de los ecosistemas, como un generador de servicios ambientales que dinamicen la economía e interaccionen en armonía con la población en general.

La selección de un sitio para un RS se constituye en un problema de análisis espacial que principalmente se enfoca en salvaguardar los recursos naturales y la salud de los habitantes. En ese marco, dentro de Latinoamérica, se avistan un total de 36 criterios, entre los más relevantes, por contemplarse en el $50 \%$ de las normas o más, se encuentran: distancia a cuerpos de agua superficiales o subterráneos, restricción de zonas de inundación, afectación a zonas urbanas y expansión, restricción de áreas naturales protegidas, inestabilidad geológica, distancia a aeropuertos, accesibilidad de vías, características mecánicas del suelo y disponibilidad de material de cobertura. Criterios que tienen una marcada orientación a la optimización de recursos económicos por parte de las autoridades competentes.

A más de las disposiciones legales que cada uno de los países analizados han generado para este fin, existe el caso colombiano. Este país ha avanzado hacia una articulación de la parte legal y técnica mediante una metodología de análisis multicriterio. En el caso de Ecuador, esta opción sería lo idóneo, puesto que tanto el COA como su reglamento, dejan ya explícitas las condiciones legales bajo las cuales se debe implementar el modelo de la GIRS y muy puntualmente los sitios de disposición final. A ello se suma la NCA, de donde se extrajeron los criterios mínimos y vigentes a la fecha de este estudio. Sin embargo, los grandes conflictos socioambientales evidencian que después de 17 años de vigencia, necesita una actualización y mejora, que vayan de la mano de los demás cuerpos legales.
En primera instancia, las entidades rectoras y competentes en el ámbito de sus jurisdicciones, deben desarrollar sus actuaciones para generar un mapeo integral de áreas declaradas como patrimonio natural, protegidas, recreación, conservación, zonas urbanas, de expansión urbana, rurales pobladas y zonas de producción agrícola. Estas últimas, en el caso de Ecuador, se deben destacar por su dependencia para el desarrollo económico. A través de una ordenanza, este inventario completo, articulado y coordinado, debería configurarse como áreas intangibles; de tal forma que estas zonas sean excluidas del análisis. En las áreas restantes, la acción sería verificar el cumplimiento del resto de criterios.

En Ecuador es imprescindible que las autoridades locales y nacionales, en el ejercicio de las competencias establecidas en la ley, acepten la existencia y viabilicen el uso de tecnologías de manejo de desechos. Por lo que se debe, de manera concomitante, sumar actividades de tratamiento, clasificación y reutilización, con el fin de que cuando los residuos vayan a ser depositados en la tierra, sean en menor cantidad, menos contaminantes y eviten impactos negativos sobre los recursos naturales y la salud pública. De manera adicional se sugiere consolidar verdaderos procesos de participación ciudadana, según lo estipula el Reglamento del COA, en donde con suficientes argumentos técnicos y científicos, se de paso a la construcción de una racionalidad colectiva. Con la implementación de los mecanismos mencionados se viabilizará la determinación final del sitio, que brinde como resultado la creación de un compromiso de las comunidades, y se plasmará en aceptación y minimizará el riesgo de bloqueo que existe en la actualidad.

La articulación entre el ordenamiento territorial y la gestión ambiental, específicamente con la selección idónea del sitio para emplazar un relleno sanitario, es evidente porque estos sitios responden también a una regulación de uso y ocupación del suelo, que parte de la planificación urbana y de gestiones políticoadministrativas. Por lo tanto es necesario que estas herramientas contemplen verdaderas estrategias de valoración de la aptitud del terreno para emplazar un RS. Por otro lado, se ha dado un proceso de consolidación informal de asentamientos humanos en zonas no planificadas, ubicándose por lo general, en zonas de alto riesgo.

Cuando se aborda el análisis para la búsqueda de un territorio adecuado para un RS, los organismos competentes deben apuntar al cumplimiento integral del derecho ambiental para fortalecer sus capacidades locales y de gestión. Por tales motivos hay que 
asumir con responsabilidad y de manera integral la protección que resalte el bienestar común sobre el bien individual. Es imperante que exista una visión basada en el desarrollo sostenible, como lo destaca la legislación ecuatoriana en materia de gestión ambiental, y que se incline hacia la prevención del daño al ecosistema, se valore el conocimiento y las tecnologías desarrolladas por la humanidad y se anticipe a los peligros y riesgos. Es fundamental actuar en conformidad con el principio de precaución normado en la Constitución de la República del Ecuador, más aún en caso de duda sobre los criterios, demostrando siempre la inexistencia del daño ambiental.

Todas las normas analizadas, si bien cuentan con ciertos criterios y exigencias mínimas, no hacen sino evocar la discusión que por décadas se ha mantenido respecto del cuidado del ambiente. Hay que aceptar que no son suficientes y que hay que precautelar con urgencia los derechos de la naturaleza en consonancia con los derechos humanos, pues la falta de recursos de ninguna manera puede ser excusa de los Estados para no asumir su responsabilidad y enfrentar el consumismo global. Es evidente la complejidad y variedad de los criterios que pretenden resolver un problema que va más allá de lo físico, para llamar a la conciencia y responsabilidad socioambiental.

La transformación de la normativa nacional, los criterios internacionales, y la visión constitucional, recogen principios de orden mundial sobre la protección del ambiente, e invitan a repensar las reglas y criterios mínimos para emplazar un sitio de disposición final en función de un concepto de desarrollo sostenible. Para emprender un proyecto de esta índole, hay que dejar de lado la práctica informal de la selección de un terreno sin estudios técnicos preliminares, con limitado presupuesto económico, ausencia de procedimientos, de regulación ambiental, sin la inclusión de verdaderos procesos de participación ciudadana. Estas prácticas, sin duda, han dejado como herencia: la afectación de la salud de la población, del agua, la flora y la fauna. Cambiar esta percepción implica mirar hacia atrás para construir un presente y un futuro mejor para las nuevas generaciones. Quedan en la visión ecuatoriana y latinoamericana, las experiencias de muchos municipios y gobiernos que han realizado trabajos en terrenos inadecuados $\mathrm{y}$ que no han respondido a las exigencias de la legislación ambiental vigente. A pesar de que todos los actores sociales se encuentran asistidos de la ley para denunciar cuando se viole el derecho de participar en la gestión ambiental y proteger el ambiente en el cual viven, la falta de apoyo gubernamental y normas claras, garantizan la impunidad.

\section{AGRADECIMIENTO}

La presente publicación se desarrolló en el marco del proyecto de investigación "Sistema mancomunado de transporte, tratamiento y disposición final de residuos sólidos para la provincia del Azuay" financiado por la Universidad Católica de Cuenca y la Empresa Pública Municipal de Aseo de Cuenca (EMAC - EP). Los autores agradecen el apoyo de todo el equipo que forma parte de este proyecto.

\section{REFERENCIAS}

Abd-El-Monsef H. y Smith S.E. (2019). Integrating remote sensing, geographic information system, and analytical hierarchy process for hazardous waste landfill site selection. Arab. J. Geosci. 12 (5), 1-14. https://doi. org/10.1007/s12517-019-4266-7

Abujayyab S.K.M., Ahamad M.S.S., Yahya A.S., Bashir M.J.K. y Aziz H.A. (2016). GIS modelling for new landfill sites: critical review of employed criteria and methods of selection criteria. IOP Conference Series: Earth and Environmental Science 37 (1), 1-17. https:// doi.org/10.1088/1755-1315/37/1/012053

Acurio G., Rossin A., Teixeira P.F. y Zepeda F. (1997). Diagnostico de la situación del manejo de residuos sólidos municipales en America Latina y el Caribe. Banco Interamericano de Desarrollo y la Organización Panamericana [en línea]. https://publications.iadb.org/ es/publicacion/15925/diagnostico-de-la-situacion-delmanejo-de-residuos-solidos-municipales-en-america $01 / 18 / 2020$

Alavi N., Goudarzi G., Babaei A.A., Jaafarzadeh N. y Hosseinzadeh M. (2013). Municipal solid waste landfill site selection with geographic information systems and analytical hierarchy process: a case study in Mahshahr County, Iran. Waste Manage. Res. 31 (1), 98-105. https://doi.org/10.1177/0734242X12456092

Asamblea Nacional Constituyente (2008). Constitución de la República del Ecuador. Montecristi, Ecuador, 135 pp.

Asamblea Nacional de la República del Ecuador (2017). Registro Oficial Suplemento 983. Código Orgánico del Ambiente. Quito, Ecuador, 99 pp.

Asamblea Nacional de la República del Ecuador (2010). Código Orgánico de Organización Territorial, Autonomía y Descentralización. Quito, Ecuador, 227 pp.

Asamblea Nacional de la República del Ecuador (2016). Registro Oficial Nro 790. Ley Orgánica de Ordenamiento Territorial, Uso y Gestión del Suelo. Quito, Ecuador, $32 \mathrm{pp}$.

BID (2015). Situación de la gestión de residuos sólidos en América Latina y el Caribe. Banco Interamericano 
de Desarrollo [en línea]. https://publications.iadb.org/ es/situacion-de-la-gestion-de-residuos-solidos-enamerica-latina-y-el-caribe 12/29/2019

Barakat A., Hilali A., Baghdadi M. El y Touhami F. (2017). Landfill site selection with GIS-based multi-criteria evaluation technique. A case study in Béni Mellal-Khouribga Region, Morocco. Environ. Earth Sci. 76 (413), 1-13. https://doi.org/10.1007/ s12665-017-6757-8

Carrasco S. y Milic I. (2017). Patrón territorial de acumulación ilegal de residuos sólidos en la cuenca alta del río Cachapoal. Personas y Sociedad 31 (1), 74-102.

Chopda M. y Malek P.A.M. (2018). Contamination of goundwater quality due to municipal solid waste disposal - A GIS Based Study. Irjet. 5 (4), 4836-4842.

Colebrook M. y Sicilia J. (2007). Undesirable facility location problems on multicriteria networks. Comput. Oper. Res. 34 (5), 1491-1514. https://doi.org/10.1016/j. cor.2005.06.010

Congreso Argentino (2004). Ley 25916. Gestión integral de residuos domiciliarios. Buenos Aires, Argentina [en línea]. http://servicios.infoleg.gob.ar/infolegInternet/ anexos/95000-99999/98327/norma.htm 12/12/2019

Congreso Nacional del Ecuador (2006). Registro Oficial Suplemento 423. Ley orgánica de salud. Quito, Ecuador, $46 \mathrm{pp}$.

Dar S.N., Wani M.A., Shah S.A. y Skinder S. (2019). Identification of suitable landfill site based on GIS in Leh, Ladakh Region. GeoJournal 84 (6), 1499-1513. https://doi.org/10.1007/s10708-018-9933-9

Demesouka O.E., Vavatsikos A.P. y Anagnostopoulos K.P. (2013). Suitability analysis for siting MSW landfills and its multicriteria spatial decision support system: method, implementation and case study. Waste Manage. 33 (5), 1190-1206. https://doi.org/10.1016/j. wasman.2013.01.030

Elahi A. y Samadyar H. (2015). Municipal solid waste landfill site selection using analytic hierarchy process method for Tafresh Town. Journal of Biodiversity and Environmental Sciences 6 (1), 9-21.

Ferronato N., Rada E.C., Gorritty Portillo M.A., Cioca L.I., Ragazzi M. y Torretta V. (2019). Introduction of the circular economy within developing regions: a comparative analysis of advantages and opportunities for waste valorization. J. Environ. Manage. 230, 366378. https://doi.org/10.1016/j.jenvman.2018.09.095

Gascón S.M., Jiménez L.M. y Pérez H. (2015). Óptima ubicación de un relleno sanitario para el área metropolitana del Valle de Aburrá empleando sistemas de información geográfica. Ingenierías USBmed 6 (1), 38-45. https://doi.org/10.21500/20275846.1722

González-Díaz J.M. (2016). Una propuesta de localización óptima para un nuevo sitio de disposición final de residuos sólidos no peligrosos para Bogotá, D.C. Perspectiva Geográfica 20 (1), 155-174. https://doi. org/10.19053/01233769.4503

Gorsevski P.V., Donevska K.R., Mitrovski C.D. y Frizado J.P. (2012). Integrating multi-criteria evaluation techniques with geographic information systems for landfill site selection: a case study using ordered weighted average. Waste Manage. 32 (2), 287-296. https://doi. org/10.1016/j.wasman.2011.09.023

Gran-Castro J.A. y Bernache-Pérez G. (2015). Gestión de residuos sólidos urbanos, capacidades del gobierno municipal y derechos ambientales. Sociedad y Ambiente 1 (9), 73-101.

Hernández-Berriel M. del C., Aguilar-Virgen Q., Taboada-González P., Lima-Morra R., EljaiekUrzola M., Márquez-Benavides L. y BuenrostroDelgado O. (2016). Generación y composición de los residuos sólidos urbanos en América Latina y el Caribe. Rev. Int. Contam. Ambie. 32 (Especial Residuos Sólidos), 11-22. https://doi.org/10.20937/ RICA.2016.32.05.02

Hettiarachchi H., Ryu S., Caucci S. y Silva R. (2018). Municipal solid waste management in Latin America and the Caribbean: issues and potential solutions from the governance perspective. Recycling 3 (19), 1-15. https://doi.org/10.3390/recycling3020019

Hoornweg D. y Bhada-Tata P. (2012). What a waste: a global review of solid waste management. Urban development series - Knowledge papers no.15. World Bank [en línea]. https://openknowledge.worldbank. org/handle/10986/17388 12/25/2019

Ihedioha J.N., Ukoha P.O. y Ekere N.R. (2017). Ecological and human health risk assessment of heavy metal contamination in soil of a municipal solid waste dump in Uyo, Nigeria. Environ. Geochem. Hlth. 39 (3), 497-515. https://doi.org/10.1007/s10653-016-9830-4

INEC (2018). Gestión de Residuos Sólidos. Boltetín Técnico Nro 01-2017 - GAD Municipales [en línea]. https://www.ecuadorencifras.gob.ec/documentos/ web-inec/Encuestas_Ambientales/Municipios_2017/ Residuos_solidos_2017/Boletin_Tecnico_Residuos_2017.pdf 12/17/2019

Jiménez Martínez N.M. (2015). La gestión integral de residuos sólidos urbanos en México: entre la intención y la realidad. Letras Verdes. Revista Latinoamericana de Estudios Socioambientales 17, 29-56. https://doi. org/10.17141/letrasverdes.17.2015.1419

Johannessen M.L. y Bayer G. (1999). Observations of solid waste landfills in developing countries: Africa, Asia and Latin America. The International Bank for Reconstruction and Development [en línea]. http://documents. worldbank.org/curated/en/393531468741627673/pdf/ multi-page.pdf 12/16/2019 
Korhonen J., Honkasalo A. y Seppälä J. (2018). Circular economy: The concept and its limitations. Ecological Economics 143, 37-46. https://doi.org/10.1016/j. ecolecon.2017.06.041

Lacoste E. y Chalmin P. (2006). From waste to resource. An abstract of 2006 World Waste Survey. Veolia Environmental Services [en línea]. http://81.47.175.201/ flagship/attachments/waste_resource.pdf 12/20/2019

Latargère J. (2019). La participación social en la gestión de los residuos sólidos. Revista Legislativa de Estudios Sociales y de Opinión Pública 12 (24), 37-57.

Li R.Y.M., Meng L., Leung T.H., Zuo J., Tang B. y Wang Y. (2018). Unmaking waste in construction in the EU and the asian circular economy: A formal institutional approach Chapter 13. En: Unmaking waste in production and consumption: towards the circular economy. (R. Crocker, C. Saint, G. Chen y Y. Tong, Eds.), pp. 225-240. https://doi.org/10.1108/978-1-78714-619-820181018

Majolagbe A.O., Adeyi A.A., Osibanjo O., Adams A.O. y Ojuri O.O. (2017). Pollution vulnerability and health risk assessment of groundwater around an engineering landfill in Lagos, Nigeria. Chemistry International 3 (31), 58-68.

Meléndez C.E. (2004). Guia práctica para la operación de celda diaria en rellenos sanitarios pequeños y medianos. PROARCA [en línea]. http://cidoc.marn. gob.sv/documentos/guia-practica-para-la-operacionde-celdas-diarias-en-rellenos-sanitarios-pequenos-ymedianos/ 12/26/2019

MAE (2003). Norma de calidad ambiental para el manejo y disposición final de desechos sólidos no peligrosos. Quito, Ecuador, 26 pp.

MAE (2015). Acuerdo No. 061 Reforma del libro VI del Texto Unificado de Legislación Secundaria. Ministerio del Ambiente. Quito, Ecuador, 80 pp.

MARENA (2002). Norma técnica N ${ }^{\circ} 05$ 013-01. Norma técnica para el control ambiental de los rellenos sanitarios para desechos sólidos no peligrosos. Ministerio del Ambiente y Recursos Naturales. Asamblea Nacional de la República de Nicaragua. 23 de abril de 2002.

Ministerio de Desarrollo Humano (1996). Norma Boliviana NB 742-760. Normas de residuos sólidos. 3 de octubre de 1996.

Musso T.B., Pettinari G., Parolo M.E. y Mesquín L. (2017). Arcillas esmectíticas de la Región Norpatagónica Argentina como barreras hidráulicas de rellenos sanitarios y agentes de retención de metales pesados. Rev. Int. Contam. Ambie. 33 (1), 141-152. https://doi. org/10.20937/RICA.2017.33.01.13

Noguera K. y Olivero-Verbel J. (2010). Los rellenos sanitarios en Latinoamerica: Caso Colombiano. Revista de la Academia Colombiana de Ciencias Exactas, Físicas y Naturales 34 (132), 347-356.
Ogunrinola I.O. y Adepegba E.O. (2012). Health and economic implications of waste dumpsites in cities: The case of Lagos, Nigeria. International Journal of Economics and Finance 4 (4), 239-251. https://doi. org/10.5539/ijef.v4n4p239

Palmeira-Wanderley V., Affonso-Fonseca F.L., ValaQuiaios A., Nuno-Domingues J., Paixão S., Figueiredo J., Ferreira A., De Almeida-Pinto C., Da Silva O.R., Alvarenga R., Machi-Junior A., Luiz Savóia E.J. y Daminello-Raimundo R. (2017). Socio-environmental and hematological profile of landfill residents (São Jorge Landfill-Sao Paulo, Brazil). Int. J. Env. Res. Pub. He. 14 (64), 1-12. https://doi.org/10.3390/ ijerph14010064

Presidencia Constitucional de la República de Honduras (2001). Acuerdo Nro. 378-2001: Reglamento para el manejo de residuos sólidos. Tegucigalpa, Honduras, 8 pp

Presidencia de la República Bolivariana de Venezuela (1992). Decreto 2216: Normas para el manejo de los desechos sólidos de origen doméstico, comercial, industrial, o de cualquier otra naturaleza que no sean peligrosos. Caracas, Venezuela, 5 pp.

Presidencia de la República de Chile (2008). Decreto 189: Reglamento sobre condiciones sanitarias y de seguridad básicas en los rellenos sanitarios. Santiago de Chile, Chile, 15 pp.

Presidencia de la República de Colombia (2005). Decreto 0838: Localización de áreas para la disposición final de residuos sólidos. Bogotá, Colombia, 17 pp.

Presidencia de la República de Costa Rica (2014). Decreto ejecutivo Nro. 38928-S: Reglamento sobre rellenos sanitarios. San José, Costa Rica, 30 pp.

Presidencia de la República de El Salvador (2002). Decreto No. 42 Reglamento especial sobre el manejo integral de los desechos sólidos. San Salvador, El Salvador, 44 pp.

Presidencia de la República de Panamá (2004). Decreto Ejecutivo Nro 275: Normas de los rellenos sanitarios, con capacidad mayor o igual a trescientas toneladas métricas por día, de residuos sólidos no peligrosos. Ciudad de Panamá, Panamá, 17 pp.

Presidencia de la República del Ecuador (2019). Suplemento Registro Oficial Nro 507. Reglamento al Código Orgánico del Ambiente. Quito, Ecuador, 286 pp.

Presidencia de la República del Perú (2017). Reglamento del Decreto Legislativo N 1278, Ley de Gestión Integral de Residuos Sólidos. Lima, Perú, 49 pp.

Quintero-Torres D.I. (2017). El papel de la gestión territorial en la ubicación de rellenos sanitarios. Caso de estudio: relleno sanitario Doña Juana, Bogotá, Colombia. Perspectiva Geográfica 21 (2), 251-276. https://doi.org/10.19053/01233769.5852

Rahmat Z.G., Niri M.V., Alavi N., Goudarzi G., Babaei A.A., Baboli Z. y Hosseinzadeh M. (2017). Landfill site 
selection using GIS and AHP: a case study: Behbahan, Iran. KSCE J. Civ. Eng. 21 (1), 111-118. https://doi. org/10.1007/s12205-016-0296-9

Rúa-Restrepo J.J., Echeverri G.I. y Colorado H.A. (2019). Toward a solid waste economy in Colombia: an analysis with respect to other leading economies and Latin America. En: The minerals, metals \& materials series (G. Gaustad, C. Fleuriault, M. Gökelma, J. A. Howarter, R. Kirchain, K. Ma, C. Meskers, N.R. Neelameggham, E. Olivetti, A.C. Powell, F. Tesfaye, D. Verhulst y M. Zhang, Eds.) REWAS 2019. Sringer, Cham, pp. 337-354. https://doi.org/10.1007/978-3030-10386-6_41

Salleh A.H., Ahamad M.S.S., Yusoff M.S. y Aziz H.A. (2017). Multiple criteria landfill site selection method incorporating the NIMBY factors. Memorias. International Conference of Global Network for Innovative Technology and AWAM International Conference in Civil Engineering. 1892 (1), 130003. 16 de octubre de 2017. https://doi.org/10.1063/1.5005759

Sánchez-Arias M., Riojas-Rodríguez H., CatalánVázquez M., Terrazas-Meraz M.A., Rosas I., Espinosa-García A.C., Santos-Luna R., Siebe C. (2019). Socio-environmental assessment of a landfill using a mixed study design: a case study from México. Waste Manage. 85, 42-59. https://doi.org/10.1016/j. wasman.2018.12.012

Sanfelice V., van Calster G. y Reins L. (2016). The application of international environmental law principles in Latin America. Compilation of a database of superior courts case-law, and initial findings. SSRN Electronic Journal (February 29). https://doi.org/10.2139/ ssrn. 2746804

SEAM (2004). Resolución Nro 282. Criterios para la selección de áreas para la disposición final de residuos sólidos en rellennos sanitarios. Secretaría del Ambiente. Asunción, Paragua, 3 pp.

Secretaría de Estado de Medio Ambiente y Recursos Naturales de República Dominicana (2003). Norma Nro. NA-RS-001-03. Norma para la gestión ambiental de residuos sólidos no peligrosos. BÚHO. Junio de 2003.

SEMARNAT (2004). Norma Oficial Mexicana NOM083-SEMARNAT-2003. Especificaciones de protección abiental para la selección del sitio, diseño, cosntrucción, operación, monitoreo, clausura y obras complemementarias de un sitio de disposición final de residuos sólidos urbanos y de manejo especial. Secretaría del Medio Ambiente y Recursos Naturales. Diario Oficial. 20 de octubre de 2004.
Şener Ş., Sener E. y Karagüzel R. (2011). Solid waste disposal site selection with GIS and AHP methodology: a case study in Senirkent-Uluborlu (Isparta) Basin, Turkey. Environ. Monit. Assess. 173, 533-554. https:// doi.org/10.1007/s10661-010-1403-x

Şener Ş., Şener E., Nas B. y Karagüzel R. (2010). Combining AHP with GIS for landfill site selection: a case study in the Lake Beyşehir catchment area (Konya, Turkey). Waste Manage. 30 (11), 2037-2046. https:// doi.org/10.1016/j.wasman.2010.05.024

Solíz-Torre M. F. (2015). Ecología política y geografía crítica de la basura en el Ecuador. Letras Verdes. Revista Latinoamericana de Estudios Socioambientales 17, 4-28. https://doi.org/10.17141/letrasverdes.17.2015.1259

Sun L., Zhu D. y Chan E.H.W. (2016). Public participation impact on environment NIMBY conflict and environmental conflict management: Comparative analysis in Shanghai and Hong Kong. Land Use Policy 58, 208217. https://doi.org/10.1016/j.landusepol.2016.07.025

Terraza H. (2009). Lineamientos estratégicos del Banco Interamericano de Desarrollo para el sector de residuos sólidos (2009 - 2013). Banco Inter-Americano de Desarrollo Nota Técnica No. IDB-TN-101 [en línea]. https://limpezaurbana.com.br/textos/manejo_de_residuos-idb-2009.pdf 12/29/2019

Uyan M. (2014). MSW landfill site selection by combining AHP with GIS for Konya, Turkey. Environ. Earth Sci. 71 (4), 1629-1639. https://doi.org/10.1007/s12665013-2567-9

Venegas-Sahagún B.A. (2018). Conflicto socioambiental y rellenos sanitarios en los pueblos de la Barranca en Zapopan, Jalisco. Carta Económica Regional 121, 193-215. https://doi.org/10.32870/cer.v0i121.7106

Vera-Toledo P. y González-Herrera R. (2010). Manejo inadecuado de residuos sólidos urbanos como una causa de la pérdida de biodiversidad en Chiapas. Lacandonia 4 (1), 65-73.

Walsh J. (2007). Marco legal e institucional de los residuos. Anales de la Academia Nacional de Ingeniería de Buenos Aires Tomo III, 267-272.

Wang G., Qin L., Li G. y Chen L. (2009). Landfill site selection using spatial information technologies and AHP: a case study in Beijing, China. J. Environ. Manage. 90 (8), 2414-2421. https://doi.org/10.1016/j. jenvman.2008.12.008 